\title{
MALENCHUS PIAUHYENSIS N. SP. (NEMATODA, TYLENCHIDAE) DE SOLO DO BRASIL*
}

\author{
Ailton Rocha Monteiro
}

\section{RESUMO}

\begin{abstract}
Malenchus piauhyensis, espécie nova para a Ciência, é descrita e figurada, com base em duas fêmeas obtidas de solo ao redor de raízes de limão cravo (Citrus limonia) no município de Campo Malor, Estado do Piaul, Brasil.
\end{abstract}

\section{INTRODUÇAOO}

ANDRÁSSY (1968) criou o gênero Malenchus, filiado à família Tylenchidae, para conter, além do tipo, Malenchus machadoi (Andrássy, 1963), uma nova espécie, Malenchus acarayensis, esta de solo de florestade-galeria do rio Acaray, no Paraguai, América do Sul. ANDRÁSSY (1963) havia originalmente descrito e filiado $\mathbf{M}$. machadoi, espécie muscícola da Africa Portuguesa (Dundo, Angola), ao gênero Aglenchus (Andrássy, 1954) Meyl, 1961.

\section{MATERIAL E METODOS}

Em material do Estado do Piauí, Brasil, que recebemos para exame nematológico, verificamos a ocorrência da nova espécie de Malenchus descrita neste trabalho.

Os espécimens foram extraídos do solo pelo método do peneiramento conjugado ao de Baermann modificado (Baermann em recipiente raso), mortos por aquecimento a $65^{\circ} \mathrm{C}$, fixados em TAF, desidratados pelo método vagaroso a partir de glicerina $2,5 \%$ em solução alcoólica $30 \%$ e montados em glicerina (lâmina permanente).

* Entregue para publicação em 11/10/74.

** Departamento de Zoologia da ESALQ. 


\section{A ESPECIE}

Malenchus piauhyensis $n$. sp. (fig. $1, A$ e B)

DIMENSÓES. Fêmeas (holótipo e parátipo, respectivamente): comprimento $=472,9$ e 505,7 micros; $\mathrm{a}=36,8$ e 39,$3 ; \mathrm{b}=5,6$ e 5,$9 ; \mathrm{c}=$ 3,8 e 3,$8 ; \mathrm{V} \%=61,6$ e 61,$3 ;$ ramo uterino posterior $\%:=1,8$ e 2,$0 ;$ e, estilete $=$ 7,0 e 7,0 micros.

DESCRIÇÃO. Fêmeas - Corpo recurvado ventralmente quando morto por aquecimento gradual. Cutícula nitidamente anelada transversalmente, com anéis ao meio do corpo medindo 1,7 micros de largura; a anelação não se estende à ponta da cauda; os anéis cuticulares diminuem de largura à medida que se aproximam da extremidade anterior; ao nível do bulbo mediano medem 1,4 micros. Campos laterais de bordos lisos, 1/6 tão largos quanto o corpo, com interior bem liso, sem incissuras longitudinais; iniciam-se a meia distância entre a base do estilete e o bulbo mediano do esôfago. Papilas cervicais (deirídios) bem desenvolvidas, situadas a cerca de 70,0 micros da extremidade anterior, ao nível do poro excretor. Fasmídios não observados.

Região labial tronco-cônica elevada, com 4 estrias (5 anéis) delicadas; largura da sua base igual a $50 \%$ da largura do corpo ao nível da base do esôfago. Anfídios como fendas longitudinais ocupando cerca de $2 / 3$ da altura da região labial.

Estilete muito delicado medindo cerca de 7,0 micros de comprimento, com bulbos basais alongados dirigidos para trás. Abertura da glândula esofagiana dorsal localizada logo após o estilete. Bulbo mediano (metacorpo) situado aos $50 \%$ do comprimento do esôfago, fusiforme, com válvula bem desenvolvida. Bulbo basal piriforme alongado. Anel nervoso situado na metade do ístmo. Poro excretor situado a 70,0 - 71,5 micros da extremidade anterior. Hemizonídio bem evidente, um anel anterior ao poro excretor. Cárdia na forma de disco. Intestino de paredes delicadas; células intestinais com poucas granulações. Reto muito delicado com comprimento igual ao diâmetro do corpo ao nível do ânus. Ânus em forma de minúsculo orifício sendo a região em que se situa um pouco elevada.

Vulva como larga fenda transversal medindo cerca de 8-9 micros, com escudos laterais não desenvolvidos. Vagina cuticularizada adentrando até cerca de $2 / 3$ do diâmetro do corpo. Aparelho reprodutor prodelfo, com ovário distendido; oócitos em fila simples. Regiões do oviduto e do útero pouco distintas. Saco uterino posterior 1,8 a 2,0\% do comprimento do corpo ou $2 / 3$ a $7 / 9$ da largura do corpo.

Cauda longa, seu comprimento igual a 2,1 a 2,2 vezes a distância vulva-ânus ou seja, 14,5 a 16,9 vezes a largura do corpo ao nível do ânus; filiformes, de extremidade lisa e bem apontada.

Machos: não encontrados.

DIAGNOSE. Malenchus piauhyensis $n$. sp. distingue-se facilmente de 
Malenchus machadoi (Andrássy, 1963) Andrássy, 1968 e de M. acarayensis Andrássy, 1968 por apresentar: a) cauda nitidamente mais longa; b) corpo mais esbelto; e, c) vulva mais anterior. De $M$. machadoi distingue-se ainda por ter: d) região labial não tão estreita em relação ao corpo e, e) estilete menor (7,0: 10,5 - 12,5 micros). De $M$. acarayensis difere também por ser espécie maior (comprimento $=0,33-0,37 \mathrm{~mm}$ em $\mathrm{M}$. acarayensis).

HABITAT E LOCALIDADE TfPICOS. Solo de rizosfera de limão cravo (Citrus limonia Osbeck) como porta-enxerto de laranjeira doce (Citrus sinensis Osbeck) no município de Monte Maior, Estado do Piaú, Brasil, coletado em 7 de agosto de 1969, pelo Eng. Agr. Dr. Alvaro Tito de Castelo Branco.

TIPOS. Duas fêmeas (holótipo e parátipo) na lâmina 386/05 da coleção nematológica do Departamento de Zoologia, Escola Superior de Agricultura «Luiz de Queiroz», Universidade de São Paulo, Piracicaba, Brasil.

\section{SUMMARY}

\section{A NEW NEMATODE SPECIES FROM SOIL OF BRAZIL}

Malenchus piauhyensis $n$. sp. from soil around lemon (Citrus limonia) roots cultivated in Campo Maior, State of Piaui, Brazil is described and figured. Males are unknown. It differs from Malenchus machadoi (Andrássy, 1963) Andrássy, 1968 and Malenchus acarayensis Andrássy, 1968 in having longer tail, slender body and anteriorly located vulva. In addition it can be distinguished from $M$. machadoi in having shorter spear (7.0:10.5-12.5 microns) and differently shaped lip region. From M. acarayensis it also differs in having longer body $(0.47-0.51: 0.33-0.37 \mathrm{~mm})$.

\section{LITERATURA CITADA}

ANDRASSY, I., 1963 - Freilebende Nematoden aus Angola, I. Einige moosbewohnende Nematoden. Publicações Culturais da Companhia de Diamantes do Angola. Lisboa, $n \cdot 66: 55-80$.

ANDRASSY. I., 1968 - Fauna Paraguayensis. 2. Nematoden aus den Galeriewaeldern des Acaray-Flusses. Opusc. Zool. Budapest, 8 (2) : 167-315. 


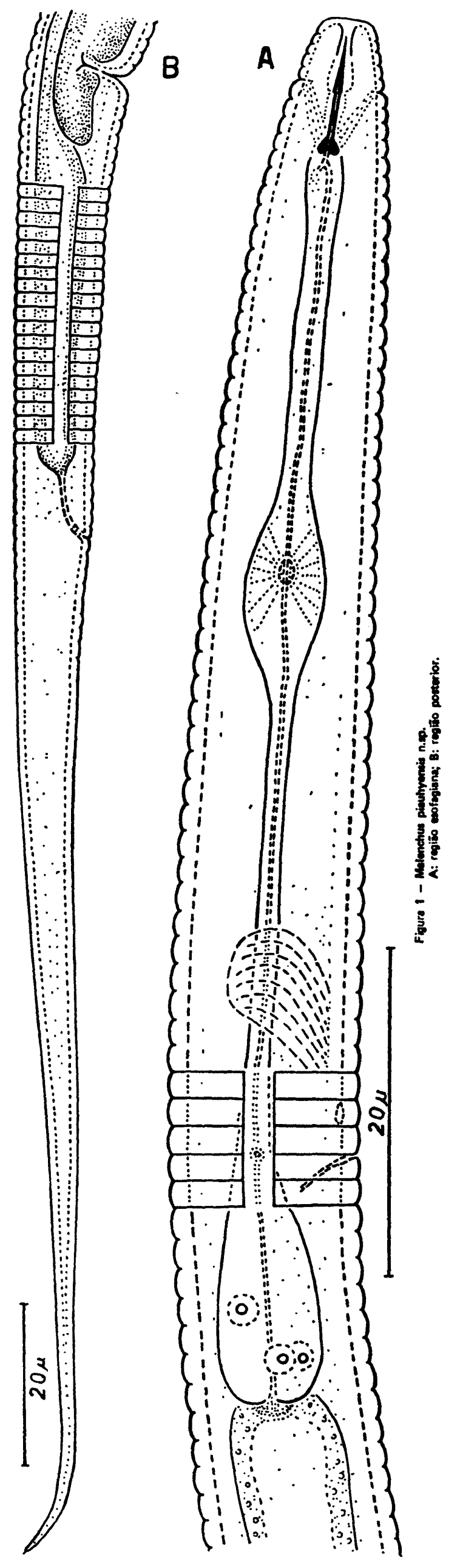

